\title{
User Friendly and Flexible Kiliani Reaction on Ketoses Using Microreaction Technology
}

\author{
Ana Cukalovic $^{1 \dagger}$, Jean-Christophe M. Monbaliu ${ }^{1 \dagger}$, Geraldine J. Heynderickx ${ }^{2}$ and Christian V. Stevens ${ }^{1 *}$ \\ ${ }^{1}$ SynBioC Research Group, Department of Sustainable Organic Chemistry and Technology, Faculty of \\ Bioscience Engineering, Ghent University, Coupure Links 653, B-9000 Gent, Belgium \\ ${ }^{2}$ Laboratory for Chemical Technology, Department of Chemical Engineering, Faculty of Engineering \\ and Architecture, Ghent University, Krijgslaan 281-S5, B-9000 Gent, Belgium
}

\begin{abstract}
The Kiliani reaction, i.e. the elongation of the carbon chain by means of cyanide addition to the carbonyl group of carbohydrate derivatives, is studied on lower C3-, C4- and C6-ketoses under continuous flow conditions. Depending on the process parameters, the corresponding cyanohydrins or $\alpha$-hydroxycarboxylic acids are obtained. A simple on-line purification of the effluent is studied using cation exchange resins. Reactions provide high yields and selectivity within short residence times, emphasizing the assets of the continuous flow process versus the batch process.
\end{abstract}

Keywords: renewable resources, ketoses, Kiliani, continuous flow process, microreactor, cyanides

\section{Introduction}

As the fossil resources on the planet are diminishing, a strong need to explore alternative chemical resources occurs in the chemical environment. Carbohydrates, being the most abundant and renewable material on Earth, are an evident choice to develop biobased chemicals. Among a myriad of possible applications, carbohydrates are valuable as starting materials for the production of chiral patterns. For instance, $\alpha$-hydroxycarboxylic acids are important building blocks for the synthesis of depsides and depsipeptides, a class of compounds that exhibits significant biological activity [1]. Carbohydrates are a readily available source for the production of these compounds. Branched sugar chirons are, however, seldom available and functionalized on commercial scale.

The Kiliani cyanohydrin synthesis is a classical reaction in carbohydrate chemistry. Elongation of the carbon chain by means of cyanide addition to the carbonyl group with preservation of the stereochemistry on the lateral chain was first reported by Kiliani as early as 1885 [2]. Over the years, several operating conditions for this reaction, with a wide range of conversion and yields, have been reported [3]. Reactions are, however, mostly reported using aldoses as starting materials, resulting in linearly elongated chains. Very little work is reported on the use of unprotected ketoses as feed. In a series of articles, Fleet et al. [4] reported on the conversion of various ketoses to a mixture of epimeric lactones, using inorganic cyanides in water. However, the required reaction times were high (24-h room temperature + 12-h reflux). The nitriles formed during the reaction were not isolated from the reaction mixture but could further react to give acetonides. The latter was purified by column chromatography and crystallization.

The presented research is part of a program dedicated to determine the applicability of microreaction technology [5] for organic synthetic transformations [6,7]. The presented work illustrates the applicability study of flow chemistry for the Kiliani reaction of lower ketoses using various cyanide sources, including diverse alkaline cyanides and acetone cyanohydrin. The main advantages of microreaction technology, such as the control of

\footnotetext{
* Author for correspondence: Chris.Stevens@UGent.be

$\dagger$ A.C. and J.C.M.M. have equally contributed to this work and share the first authorship in this Communication.
}

the local stoichiometry, the high mixing and heat exchange efficiency, the sealed micrometric reaction channels, and others, result in a significant improvement in reaction flexibility, efficiency and applicability. We have avoided the danger of released $\mathrm{HCN}$ by the use of the closed system and obtained clearly better conversions in flow than in batch (compared with literature data and own trials).

The experiments are performed using two commercial continuous flow reactor setups. The CPC CYTOS ${ }^{\circledR}$ College system [8] (total volume of $47 \mathrm{~mL}$, fully integrated with a heat exchanger) (in further text, CPC) and the X-Cube from ThalesNano [9] (total volume of $6 \mathrm{~mL}$, partially integrated with a heat exchanger) are used for this project. The CPC reactor is operated at various temperatures and at atmospheric pressure. Experiments requiring higher pressures are carried out using the X-Cube system (up to 150 bar at temperatures of up to $200^{\circ} \mathrm{C}$ ).

In the setup (Figure 1) a mixed solution of the substrate and the carboxylic acid is pumped via inlet 1 and the cyanide salt $(\mathrm{NaCN}$ or $\mathrm{KCN})$ via inlet 2 [10]. In an alternative experimental procedure, acetone cyanohydrin is used as the cyanide source (inlet 2), in combination with an organic base (inlet 1). Both inlets are operated at an equal flow (ranging from 0.4 to $2 \mathrm{~mL} / \mathrm{min}$ and 0.1 to $1 \mathrm{~mL} / \mathrm{min}$ for the CPC setup and the X-Cube setup, respectively), and the ratio of reagents is adjusted in the feeds. This is done to avoid insufficient mixing of both feed flows at low flow rates, a phenomenon commonly observed when using the CPC. The outlets of both systems are connected to vessels containing $1 \mathrm{M} \mathrm{Na}_{2} \mathrm{~S}_{2} \mathrm{O}_{3}$ and $1 \mathrm{M} \mathrm{KOH}$, respectively, in order to capture and neutralize unreacted HCN. As an additional safety measure, nitrogen is bubbled through the final solution to remove remaining traces of $\mathrm{HCN}$. The systems are stabilized until steady state is reached (1.6× internal volume) and samples are collected.

Process windows and parameters are studied on three substrates, C3-, C4- and C6-ketoses - dihydroxyacetone (DHA, 1a), L-erythrulose (1b) and D-fructose (1c). Solvents used for the experiments are methanol (solvent), water (co-solvent) and acetonitrile (co-solvent). Fresh cyanide solutions are prepared for each experiment, if necessary, using sonication for 10-15 min (additionally, this procedure proves to efficiently degas the feeding solutions, thus avoiding cavitations in the flow systems). In the experiments with DHA, the use of methanol allows complete conversion within a short reaction time; however, heavier carbohydrate homologues require the incorporation of water in 


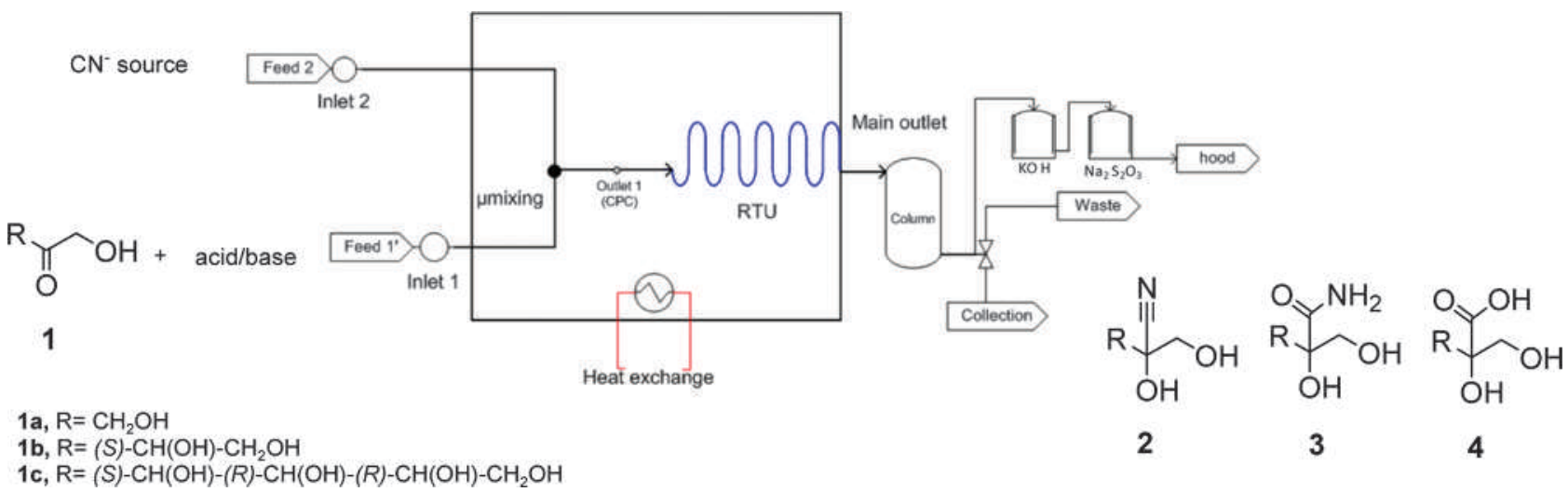

Figure 1. General setup for the flow production and hydrolysis of carbohydrate-based nitriles illustrated for the acid-catalyzed addition of alkaline cyanides

the solvent composition for solubility purposes (Table 1). The use of water invokes hydrolysis of the nitrile product. If only water is used as the reaction solvent, a complete hydrolysis of the nitrile compounds is achieved, resulting in the corresponding $\alpha$-hydroxycarboxylic derivatives (compound 4 in Figure 1). This is a remarkable result as, according to previous reports [11], nitrile hydrolysis normally demands much more severe operating conditions (longer reaction times, and higher temperatures and $\mathrm{pH}$ ). If water is used in the solvent mixture, hydrolysis occurs to a different extent, depending not only on the co-solvent used (methanol and/or acetonitrile) but also on the retention time in the reactor and the temperature. The intermediate amide (compound 3 in Figure 1) could be identified by NMR for some experiments.

In accordance with literature [12], the addition of acetonitrile to the solvent mixture is found to be beneficial for the formation of cyanohydrins. Acetonitrile is added as a co-solvent in a solvent mixture of water and methanol $(v / v / v \quad 1: 1: 3$, respectively) for some representative experiments. Ethyl acetate was tested and found to be a valuable alternative co-solvent as well.

The choice of the cation ( $\mathrm{K}$ or $\mathrm{Na}$ ) does not seem to have an effect on the conversion and product yields. The use of sodium cyanide is, however, recommended in view of the contact with the reactor material [13]. Alternatively, acetone cyanohydrin is used as a cyanide source in the presence of an organic base in catalytic quantities. Experiments are performed in an analogous manner by injecting a mixture of substrate and base catalyst (triethylamine or $N, N$-diisopropylethylamine) via one inlet (inlet 1 in Figure 1) and the solution of acetone cyanohydrin via the other (inlet 2 in Figure 1). The desired reaction occurs for both the cyanohydrin and the acid; however, the results are similar to those obtained in the first approach (with cyanide salts as $\mathrm{CN}^{-}$source and an organic acid as $\mathrm{H}^{+}$source).

A minimum temperature of $50{ }^{\circ} \mathrm{C}$ seems to be critical for the conversions, as below this point, lower conversions are observed. Residence time is a crucial parameter as well, especially for the hydrolysis reaction. Increased pressure (experiments in the X-Cube) does not seem to affect the conversion. It is rather clear from the series of performed experiments that reaction time, temperature and the solvent composition are influencing the conversions.

A simple online purification of the obtained product is considered for the experiments involving dihydroxyacetone (1a) and L-erythrulose (1b). A continuous removal of the alkaline acetate side product is initially performed by pumping the effluent through a column loaded with Amberlite IR-120. Side products are repetitively monitored by NMR analysis of the effluent for the reaction of L-erythrulose $(\mathbf{1 b})$. This problem is solved by weakening the acidic strength of the resin in the column. The cation is then successfully removed by filtration using Amberlite IRC-86 without the formation of the side products.

Filtration over Amberlite IR-120 resin was a successful way of removing the base catalyst in the trials with acetone cyanohydrin. The base was removed here by adsorption on the resin.

The Kiliani reaction performed in a batch reactor on DHA (1a) in methanol results in a $50 \%$ conversion to cyanohydrin (2a) after a residence time of $120 \mathrm{~min}$ at $25^{\circ} \mathrm{C}$ on a $3-\mathrm{mmol}$ scale (determined by the ratio of the tertiary C-3 carbon signals, Table 1 , entry 1). In contrast to this, under continuous flow conditions, a conversion of $98 \%$ is obtained after a residence time of $117.5 \mathrm{~min}$ at $25^{\circ} \mathrm{C}$ on a 30 -mmol scale (Table 1 , entry 3 ). The latter clearly emphasizes the assets of continuous flow

Table 1. Selected examples for the observed conversion of DHA and L-erythrulose under acidic conditions

\begin{tabular}{|c|c|c|c|c|c|c|c|c|c|}
\hline \multirow[b]{2}{*}{ Entry } & \multirow[b]{2}{*}{ Substrate } & \multirow[b]{2}{*}{ Ratio $\mathrm{H}^{+} / \mathrm{CN}^{-}$} & \multirow[b]{2}{*}{ Flow $^{a}(\mathrm{~mL} / \mathrm{min})$} & \multirow[b]{2}{*}{ Rt (min) } & \multirow[b]{2}{*}{$T\left({ }^{\circ} \mathrm{C}\right)$} & \multirow[b]{2}{*}{ Solvent } & \multicolumn{3}{|c|}{ Conversion $^{b, c}(\%)$} \\
\hline & & & & & & & 2 & 3 & 4 \\
\hline 1 & DHA & 1.1 & Batch & 120 & 25 & $\mathrm{MeOH}$ & 50 & - & - \\
\hline 2 & & 1.1 & Batch & 180 & 60 & $\mathrm{MeOH} / \mathrm{H}_{2} \mathrm{O}(3: 1)$ & 60 & - & 40 \\
\hline 3 & & 1.1 & 0.4 & 117.5 & 25 & $\mathrm{MeOH}$ & $>98$ & - & - \\
\hline 4 & & 1.8 & 2 & 23.5 & 50 & $\mathrm{MeOH}$ & $>99$ & - & - \\
\hline 5 & & 0.1 & 1 & 47 & 60 & $\mathrm{MeOH} / \mathrm{H}_{2} \mathrm{O}(3: 1)$ & - & - & $>99$ \\
\hline 7 & & 0.2 & Batch & 120 & 60 & $\mathrm{MeOH} / \mathrm{H}_{2} \mathrm{O}(3: 1)$ & - & 50 & 50 \\
\hline 8 & & 1.0 & 2 & 23.5 & 50 & $\mathrm{MeOH}$ & 90 & - & - \\
\hline 9 & & 1.2 & 1 & 47 & 80 & $\mathrm{H}_{2} \mathrm{O}$ & - & - & $>99$ \\
\hline
\end{tabular}

${ }^{a}$ Total flow rate.

${ }^{b}$ Conversion was determined by ${ }^{13} \mathrm{C}$ NMR with enhanced relaxation time on comparison for the ratio of C-1 signal in DHA and C-2 signal in products, trials $1-5$, and C-3 signals in erythrulose and derivatives, trials 6-9, as the relaxation times are comparable for the crude reaction mixtures.

${ }^{c}$ All experiments reported with $\mathrm{NaCN}$. 
operation versus batch operation in terms of reaction efficiency and scalability. The use of formic or acetic acid gives the same results. Increasing the temperature to $50{ }^{\circ} \mathrm{C}$ gave complete conversions in 23.5-min retention time (Table 1, entry 4). Following the filtration on the Amberlite IR-120 resin, pure cyanohydrin (2a) is obtained. A prolonged contact time with Amberlite results in a partial hydrolysis of cyanohydrin (2a). If water is introduced as a co-solvent, the resulting nitrile is hydrolyzed. Under flow conditions, this hydrolysis is complete in 47-min retention time; in comparison to this, in 3-h reaction time $\left(1 \mathrm{~h}\right.$ at $60^{\circ} \mathrm{C}$, then $2 \mathrm{~h}$ at room temperature) the conversion of the starting material is complete, but only about $40 \%$ of the produced nitrile is hydrolyzed (Table 1, entries 2 and 5). These experimental data are clearly superior to the previously reported long reaction times needed for the hydrolysis of low-chain carbohydrate nitriles (6-10 days for $\mathrm{C} 4$ nitrile derived from D-glyceraldehyde) [11].

Erythrulose results in a $90 \%$ conversion to the corresponding cyanohydrin (2b), using the optimized conditions for DHA (Table 1, entry 8 ) on a $30-\mathrm{mmol}$ scale. Complete conversion and hydrolysis to the $\alpha$-hydroxycarboxylic acid (4b) are obtained in water at $80{ }^{\circ} \mathrm{C}$ after 47 -min residence time (Table 1, entry 8). Conversion and hydrolysis are observed to change when varying the solvent mixture composition, the flow rate and the temperature. In batch on the contrary, after 60 -min reaction time at $50{ }^{\circ} \mathrm{C}$, only partial hydrolysis of the nitrile was noticed. A complete hydrolysis of the nitrile, but to a mixture of the corresponding amide and acid (2b and $\mathbf{3 b}$, in 1:1 ratio; see Table 1, entry 7) is only achieved after a reaction time of $120 \mathrm{~min}$ at $60^{\circ} \mathrm{C}$, at a $2.3-\mathrm{mmol}$ scale. This clearly proves the advantage of the flow conditions.

The alternate approach with acetone cyanohydrin as a source of cyanide and L-erythrulose led exclusively to the formation of the cyanohydrin $\mathbf{2} \mathbf{b}$ (Table 2, entry 1) using triethylamine (TEA) in methanol, while in water and using $N, N$ diisopropylethylamine (DIPEA) the complete hydrolysis to 4b was noticed (Table 2, entry 2 ).

The experiments on L-erythrulose (1b), using acetone cyanohydrin in alkaline conditions as a $\mathrm{CN}^{-}$source, lead to a difference in the stereoselectivity; i.e., a different ratio of the produced $\mathrm{C}-2$ epimers was noticed: on the trials with acetic acid as the $\mathrm{H}^{+}$source, this ratio was close to $1: 1$, and in the strongly alkaline environment, this ratio was about 1:2. Similar ratios have previously been observed and described in literature, using other substrates. This is attributed to the influence of the operating $\mathrm{pH}[14]$.

Unfortunately, under the conditions of temperature, retention time and solvent composition analogous to those in the trials with DHA and L-erythrulose, hardly any reaction is noticed in case of D-fructose (1c) as the substrate; only a slight conversion is noticed after a residence time of $117 \mathrm{~min}$ (with a minimal flow rate of $0.2 \mathrm{~mL} / \mathrm{min})$ at $55^{\circ} \mathrm{C}$, in a methanol/water $(v / v 3: 1)$ solvent mixture, using 2.4 equiv $\mathrm{KCN}$ and 5.2 equiv acetic acid. An increase in the equivalents of reactants does not influence the conversion. Possibly, longer reaction times will invoke a conversion of the fructose feed; however, this could not be tested because of the limited residence time in commercial reactors used.

The Kiliani reaction, resulting in an extension of the carbohydrate chain by the formal addition of $\mathrm{HCN}$ to a carbonyl group, is a well-known reaction and a convenient synthetic tool to open the route toward the production of $\alpha$-hydroxycarboxylic acids, important building blocks in organic chemistry. Owing to the unfavorable equilibrium conditions, it is difficult to obtain high conversions in a reasonable reaction time in a batch reactor. If a microreactor with continuous flow is used, it is possible to obtain a significant increase in reaction efficiency and go toward a complete conversion into nitriles and/or the corresponding acids, i.e., the products of an in situ nitrile hydrolysis. The introduction and the choice of an alkaline cyanide salt do not seem to have an impact on the conversions. Sodium cyanide is preferred in view of material compatibilities. In situ hydrolysis of the produced nitriles is achieved in a relatively short reaction time and under mild $\mathrm{pH}$ conditions, contrary to the results previously reported for batch operations. Addition of acetonitrile to the solvent mixture is beneficial for the feed conversion. Acetone cyanohydrin is equally successful as an alternative source of cyanide. However, the hydrolysis of the nitriles depends on the amount of available catalyst. Besides the solvent mixture and the catalyst, reaction time and temperature are certainly the most important factors influencing the obtained conversions. Purification of the products is performed in a continuous manner, by filtration of the effluent over an ion exchanger. It can be concluded that microreactor technology has proven to be beneficial for the production of useful building blocks starting from natural materials. The handling of large amounts of hydrogen cyanide is made user- and environmental-friendly by the use of a continuous flow microreactor.

\section{Materials and Methods}

2.1. General. All substrates, reactants and solvents were purchased from Sigma-Aldrich, (Belgium) and used without further purification. Fresh cyanide solutions were prepared before each run with the corresponding solvent, binary or tertiary solvent mixture, if necessary, with the aid of sonication for $10-15 \mathrm{~min}$. Water $(<0.4 \Omega)$ was deionized by a Werner Aquadem ${ }^{\circledR}$ column ion exchanger. Amberlite IRC-86 and Amberlite IR-120 resins were purchased from Sigma Aldrich, Belgium. Reactions followed and products were identified and quantified by ${ }^{13} \mathrm{C}$ NMR on a Jeol Eclipse FT 300 NMR spectrometer. Spectra were obtained in water.

2.2. Flow Reactors. The CYTOS College System reactor was manufactured by CPC - Cellular Process Chemistry Systems $\mathrm{GmbH}$. Temperature is controlled by an external heat exchange circuit via a circulation thermostat (Peter Huber Kältemaschinenbau GmbH, Huber Unistat Tango). The flow is pressuredriven via two rotary piston dispensing pumps (Ismatec ${ }^{\circledR}$, REGLO-CPF Digital, pump head: Fluid Metering Inc., FMI 005, ceramic piston, $5-50 \mu \mathrm{L}$ per stroke). The X-Cube ${ }^{\mathrm{TM}}$ system was produced by ThalesNano, Hungary, and was used without modifications.

Table 2. Selected examples for the observed conversion of L-erythrulose under basic conditions and acetone cyanohydrin

\begin{tabular}{|c|c|c|c|c|c|c|c|c|c|}
\hline \multirow[b]{2}{*}{ Entry } & \multirow[b]{2}{*}{ Base } & \multirow[b]{2}{*}{ Ratio base/CN } & \multirow[b]{2}{*}{ Flow $^{a}(\mathrm{~mL} / \mathrm{min})$} & \multirow[b]{2}{*}{ Rt (min) } & \multirow[b]{2}{*}{$T\left({ }^{\circ} \mathrm{C}\right)$} & \multirow[b]{2}{*}{ Solvent } & \multicolumn{3}{|c|}{ Conversion $^{b}(\%)$} \\
\hline & & & & & & & $2 b$ & $3 \mathbf{b}$ & $4 b$ \\
\hline 1 & TEA & 0.1 & 1.5 & 31.3 & 50 & $\mathrm{MeOH}$ & $>80$ & - & - \\
\hline
\end{tabular}


2.3. Example Run with DHA (Acidic Conditions). The general setup used for this trial is depicted in Figure 1. Prior to the reaction, the CPC reactor was flushed with the solvent (several times the internal volume of the reactor). The outlet of the reactor is connected to a column filled with Amberlite IRC-86. An example run procedure for the continuous synthesis of 2,3dihydroxy-2-(hydroxymethyl)propanenitrile (2a) typically consists of the inlet feeds charged with DHA and acetic acid at one inlet, and sodium cyanide at the other inlet, the following setup of the system (optimized conditions) has been used (Figure 1): flow 1 (DHA and acetic acid, $0.3 \mathrm{M}$ and $0.6 \mathrm{M}$, respectively, in methanol; feed 1); $1 \mathrm{~mL} / \mathrm{min}$, flow 2 (sodium cyanide $(0.36 \mathrm{M})$ in methanol; feed 2$) ; 1 \mathrm{~mL} / \mathrm{min}$. The reactor was stabilized at $50{ }^{\circ} \mathrm{C}$ over a period of $37.6 \mathrm{~min}$. 2,3-Dihydroxy-2(hydroxymethyl)propanenitrile (2a) was obtained in $>99 \%$ yield at a $4.2-\mathrm{g} \cdot \mathrm{h}^{-1}$ scale (2a): 119.7 (C1), 72.9 (C2), $62.8\left(\mathrm{C} 3, \mathrm{CH}_{2} \mathrm{OH}\right)$.

2.4. Example Run with L-Erythrulose (Basic Conditions). The general setup used for this trial is depicted in Figure 1. Prior to the reaction, the CPC reactor was flushed with the solvent (several times the internal volume of the reactor). The outlet of the reactor is connected to a column filled with Amberlite IR-120. An example run for the continuous synthesis of (3S)-2,3,4trihydroxy-2-(hydroxymethyl)butanoic acid $\mathbf{4 b}$ (as a 1:2 mixture of $2 S, 3 S$ and $2 R, 3 S$ diastereomers) typically consists of the inlet feeds charged with L-erythrulose, acetone cyanohydrin and DIPEA. The following setup of the system (optimized conditions) has been used (Figure 1): flow 1 (L-erythrulose and DIPEA, $0.08 \mathrm{M}$ and $8 \mathrm{mM}$, respectively in water; feed 1$) ; 0.5 \mathrm{~mL} / \mathrm{min}$, flow 2 (acetone cyanohydrin $(1.05 \mathrm{M})$ in water; feed 2$) ; 0.5 \mathrm{~mL} / \mathrm{min}$. The reactor was stabilized at $80{ }^{\circ} \mathrm{C}$ over a period of $75.2 \mathrm{~min}$. (3S)-2,3,4-trihydroxy-2-(hydroxymethyl)butanoic acid $\mathbf{4 b}$ was obtained in $>90 \%$ yield at a $0.8-\mathrm{g} \cdot \mathrm{h}^{-1}$ scale $(4 \mathrm{~b})$ : $176.9,176.7(\mathrm{C} 1)$;
79.5, $79.4(\mathrm{C} 2) ; 72.2,72.0(\mathrm{C} 3), 69.1,64.0\left(\mathrm{CH}_{2} \mathrm{OH}\right), 61.1,60.1$ (C4).

Acknowledgment. This work was supported by the Long Term Structural Methusalem Funding by the Flemish Government.

\section{References}

1. Yu, H.; Ballard, C.E.; Boyle, P.D.; Wang, B. Tetrahedron 2002, 58, 7663-7679.

2. (a) Kiliani, H. Ber. Dtsch. Chem. Ges. 1885, 18, 3066-3072; (b) Kiliani, H. Ber. Dtsch. Chem. Ges. 1886, 19, 221-227.

3. http://www.orgsyn.org/orgsyn/prep.asp?prep $=\mathrm{cv} 4 \mathrm{p} 0506$. Accessed 4.10.2010.

4. (a) Hotchkiss, D.J.; Soengas, R.; Simone, M.I.; van Ameijde, J.; Hunter, S.; Cowley, A.R.; Fleet, G.W.J. Tetrahedron Lett. 2004, 45, 9461-9464; (b) Soengas, R.; Izumori, K.; Simone, M.I.; Watkin, D.J.; Skytte, U.P.; Soetaert, W.; Fleet, G.W.J. Tetrahedron Lett. 2004, 46, 5755-5759.

5. Wiles, C; Watts, P. Micro Reaction Technology in Organic Synthesis; CRC Press Taylor \& Francis: Boca Raton, FL 2011; pp xxii+432.

6. (a) Acke, D.R.J. Evaluation of Microreactor Technology for Multicomponent Reactions. Ph.D. thesis, Faculty of Bioscience Engineering, Ghent University, Ghent, 2007; (b) Acke, D.R.J.; Orru, R.V.A.; Stevens, C.V. QSAR Comb. Sci. 2006, 25, 474-483; (c) Acke, D.R.J.; Stevens, C.V. Green Chem. 2007, 9, 386-390; (d) Acke, D.R.J.; Stevens, C.V.; Roman, B.I. Org. Process Res. Dev. 2008, 12, 921-928; (e) Heugebaert, T.S.A.; Roman, B.I.; De Blieck, A.; Stevens, C.V. Tetrahedron Lett. 2010, 51, 4189-4191.

7. (a) Monbaliu, J.C.M.R.; Cukalovic, A.; Marchand-Brynaert, J.; Stevens, C.V. Tetrahedron Lett. 2010, 5l, 5830-5833; (b) Monbaliu, J.C.M.R.; Winter, M.; Chevalier, B.; Schmidt, F.; Jiang, Y.; Hoogendoorn, R.; Kousemaker, M.A.; Stevens, C.V. Bioresource Technol. 2011, 102, 9304-9307.

8. Schwalbe, T.; Golbig K. et al. Eur. Pat. Appl. EP 1123734, 2001. Chem. Abstr. 2001, 135, 154468b.

9. http://www.thalesnano.com/products/x-cube. Accessed 21.10.2011.

10. http://www.cyanidecode.org/cyanide_environmental.php; Cummings,

T.F. Occup. Med.-C 2004, 54, 82-85 (Safety measures). Accessed 21.10.2011.

11. Serianni, A.S.; Nunez, H.A.; Barker, R. J. Org. Chem. 1980, 45, 3329-3341.

12. Sukata, K. Bull. Chem. Soc. Jpn. 1987, 60, 3820-3822.

13. http://www.lancevalves.com/pdfs/corrosiondata.pdf. Accessed 2.10.2010.

14. Blazer, R.M.; Whaley, T.W. J. Am. Chem. Soc. 1980, 102, 5082-5085. 